\title{
Literacy, power and practices: taking a discourse-ethnographic approach to exploring adult literacy practices in Pakistan and the UK
}

Article

Accepted Version

Capstick, T. (2019) Literacy, power and practices: taking a discourse-ethnographic approach to exploring adult literacy practices in Pakistan and the UK. International Journal of Lifelong Education, 38 (4). pp. 433-448. ISSN 1464-519X doi: https://doi.org/10.1080/02601370.2019.1636891 Available at https://centaur.reading.ac.uk/79845/

It is advisable to refer to the publisher's version if you intend to cite from the work. See Guidance on citing.

To link to this article DOI: http://dx.doi.org/10.1080/02601370.2019.1636891

Publisher: Taylor and Francis

All outputs in CentAUR are protected by Intellectual Property Rights law, including copyright law. Copyright and IPR is retained by the creators or other copyright holders. Terms and conditions for use of this material are defined in the End User Agreement. 


\section{CentAUR}

Central Archive at the University of Reading

Reading's research outputs online 


\section{INTRODUCTION}

With the aim of this special issue to question and unsettle the rising hegemony of ideologies driven by the power of international literacy surveys such as the Programme for the International Assessment of Adult Competencies (PIAAC) in the field of adult education, the current paper takes a critical approach to understanding literacy in its social and cultural contexts of use. Pakistan, as with many developing countries, literacy is measured as a skill and linked to users' ability to read and write specific texts for specific purposes (Baumgardner 1993). However, the relationship between language and literacy is not accounted for in these surveys, which has profound effects for adults writing in a second or third language. The Punjabi-Potwari-Pahari dialect chain used across the most populous parts of the country is spoken not written, though it is the home language variety of most Punjabis (Lothers and Lothers 2007). Learning to write in Urdu or English is therefore left to school for many ordinary Pakistanis who attend government-run schools rather than the more expensive but widely used private sector. Given that Mirpur is in a traditionally poor part of the Azad Kashmir region of Pakistan and access to opportunities to learn literacy in Urdu and English is very uneven across the region, the current paper seeks to explore how this uneven access influences literacy in English and Urdu for migrants to the UK at a time when proficiency in English is increasingly linked to social cohesion. Mirpur, which is known as 'Little England' by Mirpuris, has been connected to Lancashire in the North West of England for decades and has increasingly been seen as an area in which consecutive UK governments have sought to connect a lack of English language skills with social segregation (Casey 2016; Goodhart 2013). Questions of language and identity are currently at the forefront of UK-wide debates about notions of belonging in Britain. At the time this research was carried out, the Pakistani community, among other Muslim minority language groups, was facing increased pressure to demonstrate their allegiance to 'British values' through a growing conflation of English language proficiency with community cohesion (Blackledge 2005). Blackledge's analysis reveals complex chains of discourse in political actors' linking of violence on the streets of 
Lancashire, UK, in 2001 to some Asian residents' inability to speak English whereas contemporary research in critical sociolinguistics demonstrates how minority languages do not prevent migrants from belonging in their new homes if they do not learn English (Wodak 2011; Author 2018). The present study, which extends a broader PhD study which explored the multilingual literacies of a migrant family from Pakistan (Author 2016) focuses attention on the discourses about migration and literacy family members orient to when they use literacy in their everyday lives to stay in touch online as well as how they talk about these literacy practices in interviews. Conceptualising access to literacy and its relationship to discourses about language and migration in this way develops current research which accounts for literacy as a shared resource for multilingual communities (Blommaert 2008; Author 2016) and extends this research to include literacy resources in countries of origin as well as countries of settlement.

This study was carried out in an area of Pakistan which was once rural and under-developed but has over the past 60 years forged strong ties with the UK and thus has seen literacy in English pervade the local environment while Mirpur itself still remains isolated from the rest of Pakistan due to its status as a disputed territory. The discussion which follows includes an analysis of the availability of literacy as well as an investigation of how one family take up this availability in their family literacy practices. Taking this socio-cultural approach counters the dominant skill-oriented perspective on literacy by setting out a particular stance towards researching power in these literacy practices and demonstrating how all literacies are shaped by the institution in which they occur, be those institutions family, school or the bureaucracies of migration.

As an advisor working for an NGO on literacy-related education projects in 2010-2011 I worked alongside many provincial officials working in ministries of education whose work was shaped by international methods for conceptualising, measuring and understanding literacy. During this time, I was involved in country-wide research which I coordinated from Islamabad, exploring language, literacy and education in government schools. The findings of this research included making recommendations to provincial ministries and led to the 
publication of Language and Education in Pakistan: Recommendations for Policy and Practice (Coleman and Author 2012). In this report, in order to establish links between language, literacy and education across the country, I carried out interviews with staff from several provincial ministries including the government of Punjab's Literacy and Non-formal Basic Education Department which had responsibility for adult literacy programmes across the whole province of Punjab, which has a population of 110 million people. In these interviews, I was told that the definition of literacy which the department followed when carrying out its surveys was based on that developed by UNESCO relating to the three 'R's (reading, writing and arithmetic) and that this meant that the department staff considered anybody who could read and write a simple text in any language and could make calculations up to two digits was seen as a literate person. However, the respondents were not able to say which languages were used in the classrooms they were responsible for. They also recognised that there was a great deal of divergence in the literacy research in Pakistan so that the department only considered the Economic Survey of Pakistan, the Pakistan Social Livelihood Measurement Survey, the Multiple Indicator Cluster survey and the Programme Monitoring and Implementation Unit's Punjab Education Sector Reform Programme survey as reliable tools for measurement for research on literacy, all of which see literacy as a de-contextualised skill. Of particular concern was that the staff felt that the mother tongue of many of the 110 million adults across the province 'was no longer an issue' for adults' ability to read and write. One key official added, 'importance should have been given to the mother tongue at independence, that is why there is high illiteracy, 39 million illiterates, but it is too late to change this now'.

Similarly, the 2009 National Education Policy is vague about the relationship between language and literacy. The policy states that provincial education departments should have the power to choose the medium of instruction in schools up to Class V. However, this was contradicted elsewhere in the Act by the requirement that 'English shall we employed as the medium of instruction for sciences and mathematics from Class IV onwards'. The policy therefore raised a number of issues related to which language or languages should be used in secondary schools, in which subject areas, and the impact this would have on literacy for all those attending government-run schools. It seemed that this view of measuring literacy without taking account of which language users drew on in their communities neglected much of the research that has been carried out which supports a link between literacy in L1 and the benefits of learning additional languages (Cummins 2000). More recent work by Judith Kalman has also helped explain how decisions about what to read and write, by whom and when as well as the ability to interpret and compose texts have a political dimension (2005: 132). Kalman's work stresses the importance of illustrating how literacy is 
understood is not 'simply a matter of individual choice and that the attributes of a literate society go beyond the sum of the number of reading and writing individuals' (ibid).

With these concerns in mind, I began my doctoral research with the aim of carrying out ethnographic work which would help identify the links between language and literacy in a part of the country where literacy learning meant literacy in Urdu and English rather than in the home language of the majority, Punjabi (or related dialects). In the following section I explore the access to literacy in this part of Pakistan by introducing the key respondent, Usman, and his family.

\section{BACKGROUND: ACCESS TO LITERACY IN ENGLISH IN MIRPUR}

I met Usman in May 2010 in an English language school in Mirpur which was advertising 'English for visa' courses as I wanted to meet prospective migrants learning English in order to migrate to Britain which was the focus for the PhD study. The debates about the use of English in schools in Pakistan outlined above often neglect the hybridity of school-based multilingualism which I observed in schools across Pakistan and particularly in schools with untrained teachers such as Usman's. Although English is seen as a prestige language in Azad Kashmir and in wider Pakistan, I was also told of the importance of Mirpuri Punjabi at home, when teaching young children to speak but that Urdu and English were the languages of the majority of classrooms. Mirpuri is spoken widely across AK, though it is rarely written and therefore not a school-based literacy, though I was told by several teachers interviewed for this study that they feel compelled to use Mirpuri Punjabi in their classrooms as it is their 'native language'. Coleman and Author (2012) found that many Mirpuris favoured the use of Mirpuri in schools while others were less enthusiastic given that it was seen as 'low-status'. Though there was considerable divergence of opinion about the language in education situation in Pakistan, the authors of the study were able to conclude that many children in the country have limited exposure to educational opportunities and that language is one factor that contributes to that discriminatory situation (2012: 78) in a country where UNICEF estimates 6.5 million primary-aged children are out of school (2013).

At the time of meeting Usman, news that the UK was introducing English language testing for migrants from November 2010 had started to make its way around AK. Private English language schools had started to open up with courses tailored specifically to 'English for spouses' and 'English for visa'. I visited several of these schools and interviewed staff and students who, like Usman, had come to the school to take an English language test. Usman had recently married a British Mirpuri woman, Nadia, who had visited for a month 
earlier that year when they had married and she had fallen pregnant, before returning to the UK. Usman had not considered migration until his father was approached by Nadia's family in the UK with the suggestion that their children might be married. Nadia (in Lancashire) had seen Usman (in Mirpur) in a wedding video that had been brought to the UK by relatives. Nadia was looking for a second husband having recently divorced and therefore decided to travel to Mirpur to meet Usman, who agreed to the marriage on meeting Nadia. When I first met Usman he was in the process of preparing his second visa application to join his wife in England as the first application had failed. I analyse these visa literacies in a separate study (Author 2016b). One of the reasons for this failure was that Usman and Nadia, their solicitor told them, had not been able to demonstrate that their marriage was not a 'sham' when filling in the visa application forms. The 'sham' marriage discourse is a dominant discourse in the UK which conflates many Pakistani's desire to fulfil their kinship responsibilities by marrying a member from their caste with a lack of desire to 'integrate' (Harriss and Shaw 2008). Proficiency in English is a key feature of this discourse. The current paper seeks to understand the role of English in Usman's families' literacies in order to identify how English, as well as Urdu and Mirpuri, are deployed across their shared literacy resources.

Usman was born in Pakistan close to the boundary with AK though his two brothers and one sister were born in different towns across the country as their father, a soldier, was relocated to different garrisons. Usman recalled that the army schools he attended promoted literacy in Urdu by rote learning but many of the teachers spoke English, whereas the English medium schools he attended were less consistent: many of the teachers promoted literacy in Urdu and English while using spoken Urdu with code-switching to English in the classroom. For him, before university where English was used more widely, English as a medium was 'totally different from Urdu medium 'cos the books were in English'. Usman recalled several grammar books that he kept and used at home with his brothers, as he found grammar books particularly useful for developing both his spoken and written English. The young men would often sit down together to look through these books. Usman felt this was very important as he explained that schools did not always teach English properly. Here, literacy in English practised at home is related to the accessibility of literacy at school (Kalman 2005). When schools promote the availability of literacy in English through curricula, exams and written material in English, but simultaneously withhold access to literacy in English due to the lack of proficient teachers who know how to use either written or spoken English, families find alternative ways to help each other. Judith Kalman's view of this literacy mediation is that family members of different generations take up new opportunities to participate in reading and writing events and to learn new literacy practices (2005). These practices she calls literacy-scaffolding situations. Usman's family scaffold 
each other's literacy when doing homework together, an after-school activity. This provides Usman with opportunities to practise his English while at the same time giving his brothers opportunities to use their spoken and written English. Barton and Hamilton suggest that individuals move in and out of different domains and occupy the borderlands between them while changing their lives. Moreover, they find the home is the core domain to which other domains relate, 'it is a place where different aspects of life are negotiated and fitted in with each other. In this process new, hybrid practices are sometimes produced' (1998: 189). It was as part of this literacy scaffolding and mediation among family members at home that Usman felt his creativity with English, discussed below, began.

\section{Theoretical framework}

Two overarching theoretical traditions are drawn on in this study: the social practices approach to the study of literacy as situated practice, generally referred to under the label New Literacy Studies (NLS), and the Discourse-historical Approach (DHA) in Critical Discourse Studies (CDS) (see Reisigl \& Wodak 2009). NLS concentrates on the analysis of texts and practices. Barton and Hamilton (2000) claim that practices are given their structure by social institutions, such as the family and schools. As with other studies located in the NLS tradition, I talk about literacies in the plural in order to capture the range of activities and meanings, and the variety of domains, in which literacy practices occur. This means recognizing the diversity of literacy practices and the different types of texts associated with different domains (Street1984; Barton 1994; Gee 1990). However, domains are not clear-cut and boundaries between them are permeable. This permeability is central to the theoretical framework of this study, which takes the blurring of boundaries between home and school as well as the blurring of boundaries between technologies (Androutsopoulos 2014). For Barton and Hamilton, vernacular literacy practices serve everyday purposes and are rooted in everyday experiences, as well as being voluntary and self-regulated (1998). Tracing the origins of Usman's vernacular literacies highlights how those practices are neither accidental nor random but are given their structure by schools and family members. These institutions also included those which are more formally structured through rules and procedures, not teaching literacy in Mirpuri, as well as penalties, for example punishing students for using spoken Mirpuri in class instead of Urdu and English, as Usman was. The study therefore investigates the ways in which institutions, with the power to shape literacy, both support dominant literacy practices while suppressing non-dominant literacy practices. Taking this approach requires a stance on what is meant by power when Barton and Hamilton argue that 'literacy practices' are 'patterned by social institutions and power relationships, and some literacies are more dominant, visible and influential than others' (2000: 12). In the broader PhD study (Author 2016) I identified how 
dominant literacies were accessed in Mirpur. In the current paper I am concerned with the less visible literacies of participants' home languages as these also play a role in migrants' construction of multiple belongings, particularly after their migrations, at a time when proficiency in English is linked to social cohesion.

Building on the central claim outlined above by Barton and Hamilton, that some literacies are more dominant and visible than others, Tusting argues that a focus on how these processes have occurred over time can lead to a more fruitful understanding of power relations and literacy practices (2000). This, she suggests, can lead to challenging the power relations that make some literacies more powerful than others. With this in mind, it is an aim of this study to examine how migrants do not go as far as challenging the power relations that make their migration from Azad Kashmir to Lancashire difficult, but rather how they go about appropriating the literacies that make their migration successful. Castells argues that 'power is exercised by means of coercion (or the possibility of it) and/or by the construction of meaning on the basis of the discourses through which social actors guide their action' (2009: 10). Thus, according to Castells, these relationships play out by threats of violence or through discourses that constitute social action. Power is certainly exercised in Pakistan by means of coercion, as the military has always loomed large in the running of the country. In 2013 Asif Ali Zardari was the first democratically elected president to complete a full five-year term and not be ousted from his position by the military (Crilly 2013). It is, however, primarily the construction of meaning on the basis of institutional discourses about language use and belonging, and not the basis of coercion, that this study is interested, though of course coercion takes place when migrants from non-European Economic Authority countries are coerced into taking English language tests in order to fulfil their visa requirements.

\section{Methodology}

The methodological framework put together for this study combines a literacy practices approach with work carried out in the Discourse Historical Approach in Critical Discourse Studies. Although scholars the latter tradition have taken an ethnographic perspective to their work (Kryzanowski 2008), in the current paper I suggest that ethnography can enhance discourse analysis through its focus on text production and interpretation, by drawing on fieldnotes from visits to Usman's home for example, through the significance it attaches to the insider perspective which is given less prominence in discourse analysis broadly. Though Wodak and Krzyżanowski's work does include interviews and participant observation, they do not claim to prioritise the emic view to the same extent as does literacy studies. Interviews 
with text producers can reveal reasons for semiotic choices that the text analyst is unlikely to discover. The DHA's ethnographic approach has sought to overcome these limitations by intensive fieldwork within institutions. In NLS, however, researchers aim to 'suspend judgement about what constitutes literacy for the people they are working with, until they can understand what it means for the people themselves' (Maybin 2000: 199). One difference between NLS and the discourse-ethnographic approach therefore lies in the latter's focus on the institutional setting rather than NLS's focus on relating a text's meaning to its user's account of what it is about and what they do with it. A literacy practices approach seeks to examine texts from a variety of domains, often capturing the vernacular literacies of text producers, whereas the DHA thus far has concerned itself with dominant literacies within organisational contexts (such as hospitals, schools, crisis intervention centres, EU organisations and so forth; Krzyżanowski 2011; Krzyżanowski and Oberhuber 2007; Wodak 1996, 2009; Wodak et al. 2012).

The second significant aspect of the methodological approach foregrounded here is the problem-oriented, 'social wrong' aspect which Critical Discourse Studies seeks to take as its central orientation. CDA's roots in critical theory make its problem-oriented approach different to NLS. NLS also draws from different disciplines, including cross-cultural psychology, anthropology and Applied Linguistics. Although the DHA in CDA also seeks to employ a range of methods and disciplines, and with a variety of empirical data sets (Wodak 2008), its disciplinary boundaries are united by the underlying principle that the object under investigation is a complex social problem. Although many studies in NLS aim to investigate social problems in society, this is not a defining characteristic. The DHA on the other hand specifically aims to understand how social 'wrongs' are discursively constructed. How I aim to combine the two approaches is by demonstrating how social wrongs related to minority language speakers in the UK, and their use of languages other than English, are textually mediated when migrants scaffold each other's literacy.

\section{Selecting data and methods of analysis}

This study is part of a larger four-year ethnography of the multilingual literacy practices of migrants in Pakistan and the UK. The data collection for the part of the study presented here focused primarily on semi-structured interviews with participants about their literacy practices and included the collection of writing collected in Mirpur (AK) and Lancashire (UK). The selection of data via the analysis of textual material from the interviews with key respondents is based on the DHA by identifying key themes among the analysed instances of discourse in 
interviews and using these discourse topics to select data for each of the data sets. Drawing on Krzyżanowski (2008), I define the basic analytic category 'discourse topic' as 'expressed by several sentences in discourse ... by larger segments of the discourse or by the discourse as a whole' (van Dijk 1984: 56). In this sense, a discourse topic is defined as the salient theme or idea that underlies the meaning of a series of sentences. Discourse topics therefore organise the interviews thematically. These interviews were primarily framed by questions about the participants' literacy practices related to their migration. Thus, all the discourse topics relate to migration, which I will call the macro-topic as I am dealing with discourse about migration. Re-analysing the data for the current study when coding for discourses about migration and literacy, I identified various sub-topics (see also Reisgl and Wodak 2009). These were related to Mirpuri Punjabi, Urdu and English. The interviews which were chosen were those where participants spoke in the greatest detail about migration and literacy in different languages; they were analysed quantitatively by looking at references to migration and literacy. This meant counting the statistical frequency with which participants referred to migration and literacy or described an aspect of their migration in relation to literacy; thereafter, identifying topics, when discussing the matters framed by the macro topic, were 'put forth by the participants themselves' (Krzyżanowski 2008: 174). Once I had established the three sub-topics I returned to my interview transcripts and coded the data using the sub-topics as categories for data selection. In this way I was able to narrow down the data and focus on those sections that were related to migration, language and literacy.

\section{ANALYSIS}

\section{Access and availability of literacy in Mirpur}

In the analysis which follows I examine the availability of written material and the opportunities that transnational families have in Mirpur for participating in reading and writing activities which I characterize as access to literacy (Kalman 2005). For Kalman, writing practices are shaped to fit the social context in which they are employed. However, Kalman is careful to emphasize that written culture is not automatically accessed by the mere physical presence of written materials, since texts may be available but not everyone is able to read them. She builds a framework by which contexts for using literacy and learning to read and write can be explored by expanding the notion of a literacy-generating space to include three types of situation. Literacy-generating spaces refer to situations that require knowledge and the use of literacy in order for people to participate in them. Literacy scaffolding helps identify opportunities for learning about literacy through 
collaboration with others. And thirdly, voluntary literacy situations are those in which readers and writers choose to use literacy because they wish to do so (2005).

Accounting for the access and availability of literacy for migrant families in Mirpur required participant observation in the schools where I was told in interviews that prospective migrants were either learning English or taking a test in English in order to migrate. In the following section I present only the analysis related to literacy scaffolding due to space constraints. However, the ethnographic detail is paramount in a literacy practices approach, thus the analysis begins there.

By visiting Usman's home I learned that the family kept a variety of written texts, most of which were related to the family's religious practices, schoolwork and English language learning. When visiting his home I saw lots of evidence of Usman's desire to learn about English. He almost always made a point of telling me who had recommended the family's books. These were normally people who Usman knew from around Mirpur but were not normally his school teachers. The father of one of Usman's closest friends had not only recommended books but had also given Usman informal instruction in English at his home. Usman explained that he shared these books with his brothers. He felt a responsibility to help them both with their English language development. He did not see a need for his sister to learn English, though she too was learning at school.

\section{Literacy scaffolding: between home and school}

Part of the help Usman gave his brothers the young men would often sit down together to look through these books. Usman felt this was very important as he explained that schools did not always teach English properly. Here, literacy in English practised at home is related to the accessibility of literacy at school. When schools promote the availability of literacy in English through curricula, exams and written material in English, but simultaneously withhold access to literacy in English due to the lack of proficient teachers who know how to use either written or spoken English, families find alternative ways to help each other. Kalman's view is that family members of different generations take up new opportunities to participate in reading and writing events and to learn new literacy practices (2005). These she calls literacy-scaffolding situations. Usman's family scaffold each other's literacy when doing homework together, an after-school activity, which Kalman describes as devised for children but in which others participate. This provides Usman with opportunities to practise his English while at the same 
time giving his brothers opportunities to use their spoken and written English. Barton and Hamilton suggest that individuals move in and out of different domains and occupy the borderlands between them while changing their lives. Moreover, they find the home is the core domain to which other domains relate, 'it is a place where different aspects of life are negotiated and fitted in with each other. In this process new, hybrid practices are sometimes produced' (1998: 189). It is this hybridity which is explored in the following analysis when Usman continues to scaffold his friends' and family's literacies when he goes online after his migration to the UK.

When Usman started work in the UK he continued to access the Internet via his mobile phone in the taxi office where he worked. With much easier access to the Internet at home and work, his primary online literacy practices cut across these two domains of home and work. After using email most frequently in Mirpur, then instant messaging after his arrival in Lancashire, at this point the analysis of the ethnographic fieldnotes identified that Usman was spending increasing amounts of time communicating via the photo-posting feature of Facebook. This was because his wife had bought Usman a smartphone soon after his arrival in the UK. Usman's literacy practices changed as the affordances of the smartphone allowed him to access the Internet outside the home and take photographs which he introduced more easily into his communications. The analysis revealed that Usman went online largely in the afternoons, before going to work, though he often logged into his Facebook profile to chat during late shifts at work. Usman began to use the photo-posting feature to upload pictures of himself and his son, Oman, as well as pictures of the local area.

The analysis which follows is broken down into three parts. In Part 1 I present an extract from the analysis which relates to Usman's use of Mirpuri online. In Part 2 I present part of the analysis which relates to Usman's use of Urdu online, and in Part 3 I focus on the analysis pf Usman and his families' use of English online. The analysis relates to Usman's Facebook postings where he and seven of his friends and family's responses to Usman's posting of a photograph of himself shopping in the Trafford Centre shopping mall in Greater Manchester.

\section{Transcript of the Facebook postings}

Translation for extracts:

Bold italic $=$ Mirpuri Punjabi

Italic $=$ Urdu

Bold = English 
Salman: teri o phet gaya ha tou to $: P$

(you look 'spoiled' :P)

Usman: Pai ji kha pi kay say jao to yehi hoga na lol

(this is what happens when you eat too much and go to sleep lol)

Salman: (aho a $v$ gal sahi ha ahir d...ka yahi kam to hota khata peta $\mathrm{n}$ sata

(that's true, after all, that's all there is to do, eat, drink and sleep)

Salman: tou abi tk jag raha ha? Ghar ki chokidari :P

(Why are you still up? Are you nightguarding :P)

Usman: Kutay job pe hun haraami

(Dog I'm at the job bastard)

Salman: chokidari ki job gud job pc ktna pound kma raha ha?

(It's a gud job of nightwatchman you know how many pounds are you earning from that?)

\section{Part 1: Mirpur Punjabi}

The extract begins with an exchange between Salman and Usman in Mirpuri. Mirpuri is not often found written in public domains because it is an informal spoken variety which does not carry the same prestige, outside domestic contexts, as Urdu or English. Written Mirpuri would not have been available to the interactants in school or any other public domains in Pakistan. They have gained access to this through their own literacy scaffolding, firstly, Usman told me in interview in Pakistan, through their use of spoken Mirpuri, and then through their creative experiments with Mirpuri using romanized script in their digital literacies, such as in email and text messaging on their mobile phones. This leakage between domain boundaries began in Mirpur but was extended when Usman started using a smartphone in the UK.

Later in the Trafford postings, Usman's favourite cousin, Imran, who lives in Malaysia, responds to the photograph:

Imran: ooo very nice usman

Usman: Oho lala Imran kya haal hain aap kay

[Translation: Usman: Oho big brother imran how are you?]

Imran comments in English that he thinks Usman's photograph is nice. Usman replies by asking respectfully how Imran is.

I met Usman's cousin Imran during one of my visits to Usman's grandmother's village in Azad Kashmir the previous year where he told me, in English, about his life in Malaysia. During my 
visits the family used spoken Mirpuri with each other. Usman explained that he and Imran would certainly use Mirpuri if they were chatting together, but online Imran has chosen to post in English. Usman, on the other hand, responds in formal Urdu as a sign of respect to his older cousin. However, within the two dominant languages of standard English and standard Urdu, Usman incorporates the use of what he called a 'pure Pahari' word 'lala'. He explained that 'lala' meaning 'big brother' in Pahari (Mirpuri), is also now used in Urdu. Usman explained that:

the persons who do Urdu they do lala because lala is a good word in Urdu they'd say to their friends lala, lala means er, originally this word means big brother in Pahari

This perspective counters the view that named languages are homogenous given the blurring of boundaries between Urdu and Pahari/Mirpuri. Usman argues convincingly that the word 'lala', from the minority 'ethnic' language Pahari, is making its way into the dominant language, Urdu. Usman went on to explain that the word means 'big brother' and is used specifically for blood relations in Mirpuri but that it took on a new meaning when it became incorporated into Urdu:

but now that the Urdu and Pahari meets and all that this word's been used by Urdus and all that they say lala we've got we've got the poets sayin' it sayin' you know changin' their names to lala.

Here Usman describes the Urdu language poets of Pakistan, seen by many in the country as custodians of Islamic culture, who he claims have started to use the term 'lala' because he explained later that it shows respect and not its original meaning of 'big brother'. This is an example of how languages cannot be seen as discrete and impermeable autonomous systems (Bailey 2007; Blackledge and Creese 2010; 2014; Gal 2006) as poets access linguistic resources made available from across Pakistan. This illustrates what Makoni and Mashri (2007) call for when suggesting research is needed which describes how vernaculars leak into one another, suggesting that challenging existing ideas about the homogeneity of languages can lead to alternative ways of conceptualizing the status of individuals and collectives in the world. This illustrates how literacies cut across domains and blurs the boundaries between languages when migrants migrate. Usman's description in the extract here demonstrates that languages are permeable and that monolingualism is not the natural state of human life which, Gal argues, is taken to be in the powerful discourse of monolingualism (2006). This decoupling of the link between language and nation supports Levitt's claim that the transnational optic enables new unbounded understandings of the nation-state (2016: 223). This 
unboundedness is seen here in the use of the Mirpuri word lala, now a borrowed word in Urdu, and the unbounded social ties that Imam and Usman extend by sharing these literacies in the transnational space of Facebook.

\section{Part 2: Urdu}

When I asked Usman why Salman switched to Urdu in the extract above, he replied:

It's in Urdu but like the modern day Urdu, like the Urdu that persons like me will speak not the persons like er who got the got the good but of Urdu 'cause first there was too much Urdu in our curriculum, social studies in Urdu, but now the social studies is in English and all that, so now there's more English, so the kids went to so the kids goes to the slang Urdu like that [points to written abbreviated Urdu in the transcript in front of us]

Usman creates a dichotomy between standard and non-standard Urdu. Many metonymies are used such as the simile 'like modern day Urdu'. The presupposition is that young people's use of non-standard Urdu is a result of the shifts in the medium of instruction at school for certain subjects. In this sense, Urdu is shared between the domains of school and home but shifts in form and function as it travels between the two. Usman implies that there is a link between language use at school and the use of literacy outside of school, given that Usman is describing his friend's use of Urdu in Facebook postings. He argues that his use of 'modern' Urdu, as one of the 'kids', could be perceived as a reaction to the use of standard Urdu and English in schools. He suggests, through erasure, that the difference is a result of the medium of instruction for school subjects, thus presenting an insight into the origins of his transnational literacies when explaining the Trafford postings. This interview took place when Usman was using a lot of spoken Mirpuri with the older taxi drivers at the office. In a later strip he explained 'the men all speak slang here'. Usman's meaning-making appears to demonstrate the differences he was experiencing in the way Urdu was used in Lancashire compared to Mirpur and illustrates that the boundaries between literacy learning at school and literacy learning at home are blurred, particularly when dominant literacies such as formal Urdu are taken up informally as 'slang'.

\section{Part 3: English}

In Part 3, the online communication is from Facebook's Instant Messaging and occurred when Usman and I were sitting at the laptop wit Facebook open, discussing the Trafford postings. Usman and I were reading his postings when 'what's going on?' appeared on Instant Message, written by his younger brother Zahir. 


\section{Extract from interview}

Tony: why is your brother writing to you in English?

Usman: Every time this one every time yeah

Tony: Really. Why would he do that?

Usman: I don't know 'cause I told him to do that, it's good

Tony: Really

Usman: Look at that [pointing to Zahir's on-screen written English and quoting Zahir's words] 'what's going on?' he's alright with English, he's very much alright with English

Tony: Yeah I know they're alright with English but...

Usman [interrupting]: why do they choose it? 'cause 'cause this one [Zahir] he don't use mobile as much he has the thing with the mobiles. I use mobiles so much so I know I can [pointing to abbreviated word] what does that mean and all that. He don't use mobiles as much

Tony: Ah right so you can understand some of the...

Usman ...some of the slang and all that cos I used to do it but he never do it

Tony: Ah OK

Usman: You know he just studies and so he knows English

Usman begins with hyperbole: 'every time this one' and suggests that he was the reason for Zahir's use of written English. This role of literacy mediator was a common feature of Usman's family responsibilities prior to his migration and he continues with this role online from Lancashire. The intensification strategy, 'he's alright with English' helps Usman to construct his brother Zahir as a good user of English, which seems to be important to him.

In 'He don't use mobiles as much' Usman constructs a relationship between using mobile phones and developing the ability to use the implied language forms of slang Urdu. He links his own creativity with digital literacy and his use of mobile phones. This is confirmed with "he never does it' and the intensifying 'just/so' in 'he just studies so he knows English'. English connotes formal standard English. There appears to be an implicit opposition between learning standard English in one's studies and learning non-standard English on a mobile phone. For Usman, it would seem the boundaries between language varieties are broken down when he 
takes up the affordances of new technologies (mobile phones). The argument runs: if Zahir would use his mobile phone more for writing texts messages he would also be able to use 'slang' English, the implied language form, like Usman. The value of literacy in non-standard English, therefore, in the individual user's ability to extend their language practices as part of their creativity with technology (see Barton and Lee 2013). For Usman his literacy in nonstandard varieties are perhaps higher in value because his literacy practices enable him to move across the boundaries of language varieties. What for him is an affordance of mobile phones is a constraint for Zahir.

\section{Conclusion}

Taking Kalman's view that the attributes of a literate society extend much further than the sum of the number of readers and writers, the paper presented here has looked in depth at the availability of literacy in one part of Pakistan and how one family take up that availability in their access to literacy in Urdu and English. This was achieved by interrogating the view of Barton and Hamilton (1998) that literacy is shaped by institutions, both formal and informal, such as school and family. I was then able to analyse the relationship between literacy, language and migration and established how access to literacy at school and at home in Pakistan provide access to the literacies online, on Facebook, post-migration. These findings demonstrate that though everyday literacies may be self-sponsored, as in the case of the Facebook postings, they involve scaffolding from others. The analysis illustrates that an important aspect of these literacies is that they are shaped by the socio-historical influences that have shaped access to literacy in Urdu and English while constraining access to literacy in Miruri. Mirpuris subvert this lack of access to literacy in their home language at school when they when they appropriate scripts for Mirpuri Punjabi and non-standard varieties of Urdu and English. Usman's description of his literacies suggests that they are, on the one hand, a continuation of the pre-migration literacies which he developed offline at school in Pakistan but which have scaled out to other domains of practice when he uses 'slang Urdu' online in the UK. The vernacularisation which takes place when Usman uses 'slang' varieties of standard forms of Urdu and English demonstrates how local dynamics become incorporated 
into global dynamics when family members scaffold each other's literacy transnationally. By doing this Usman challenges the unequal relationship between users of standard and nonstandard Englishes and chooses to circulate practices which he feels are important for his brother to know regardless of geography. This suggests that English does have a role in maintaining family relations, though this may not be the same standard varieties of English which are tested in the international tests which migrants must pass to obtain a visa (Casciani 2010).

To build the methodological framework for this study, I combined a literacy practices approach with work in the Discourse Historical Approach in Critical Discourse Studies in order to understand how literacy practices are patterned by power relationships. This enabled me to see how the availability of literacy is accessed by Mirpuris. Firstly, I demonstrated that literacy in Urdu and English is available in Mirpur in many domains, including schools, universities and homes, as there are many English and Urdu language learning materials in these domains for those, like Usman, who can gain entry. Secondly, it was clear that Usman and his brothers take up this availability and make use of literacy in Urdu and English in the home. English literacy is available in schools but access is not granted due to the poor quality of teaching, and so learners must turn to each other in collaboration, as Usman and his brothers did, to develop the varieties of English that the family would continue to use after his migration to the UK.

\section{REFERENCES}

Androutsopoulos, J. (2014). Mediatization and sociolinguistic change: Key concepts, research traditions, open issues. In J. Androutsopoulos (Ed.), Mediatization and sociolinguistic change (pp. 3-48). Berlin: Mouton De Grutyer.

Bailey, Benjamin. (2007). Heteroglossia and boundaries. In Monica Heller (ed.) Bilingualism: A social Approach. Basingstoke: Palgrave Macmillan. 257-276

Barton, David. (1994). Literacy: An Introduction to the Ecology of Written Language. Oxford: Blackwell. 
Barton, David and Mary Hamilton. (1998). Local Literacies. London: Routledge.

Barton, David and Mary Hamilton. (2000). Literacy practices. In David Barton, Mary Hamilton and Roz Ivanič (eds) Situated Literacies: Reading and Writing in Context . London: Routledge. 7-15.

Barton, David and Carmen Lee. (2013). Language Online: Investigating Digital Texts and Practices. London: Routledge.

Baumgardner, R.J. (ed) (1993). The English Language in Pakistan. Karachi: Oxford University Press.

Blackledge, Adrian. (2005). Discourse and Power in a Multilingual World. Amsterdam: John Benjamins.

Blackledge, Adrian and Angela Creese. (2010). Multilingualism. London: Continuum.

Blackledge, Adrian and Angela Creese. (2014). Heteroglossia as practice and pedagogy. In Adrian Blackledge and Angela Creese (eds) Heteroglossia as Practice and Pedagogy London: Springer. 1-21.

Blommaert, J. (2008). Grassroots Literacy. Routledge.

Author, . (2016a), Multilingual Literacies, Identities and Ideologies: Exploring Chain Migration from Pakistan to the UK, Basingstoke: Palgrave Macmillan.

Author, . (2016b), 'Literacy Mediation in Marriage Migration from Pakistan to the UK:

Challenging Bureaucratic Discourses to Get a Visa', Discourse and Society, 27(5): 481-499

Author, . (2018). Home Literacies: The Access and Availability of Written Material in the Homes of Mirpuri Migrants in Pakistan and the UK in Bahun, S., \& Petrić, B. (Eds.) Thinking home: Interdisciplinary dialogues. London: Bloomsbury.

Castells, M. (2009). Communication power. Oxford: Oxford University Press. 
Casciani, David. (2010). June 9. English rules tightened for immigrant partners. BBC News UK. Retrieved from: http://www.bbc.co.uk/news/10270797.

Coleman, H. \& Author, T. (2012). Language in education in Pakistan: Policy recommendations. Islamabad: British Council Pakistan. Retrieved from: http://www.teachingenglish.org.uk/sites/teacheng/files/Language\%20In\%20Education \%20in\%20Pakistan.pdf.

Crilly, R. (2013, September 8). Pakistan's president steps down after completing historic full term. The Telegraph. Retrieved from: http://www.telegraph.co.uk/news/worldnews/asia/pakistan/10294303/Pakistanspresident-steps-down-after-completing-historic-full-term.html.

Cummins, J. (2000). Language, power and pedagogy. Clevedon: Multilingual Matters.

Gal, Susan. (2006). Migration, minorities and multilingualism: Language ideologies in Europe. In Clare Mar-Molinero and Patrick Stevenson (eds), Language Ideologies, Policies and Practices. Language and the Future of Europe Basingstoke: Palgrave Macmillan. 13-27.

Gee, James Paul. (1990). Social Linguistics and Literacies: Ideology in Discourses. London: Taylor and Francis.

Goodhart, David. (2013). The British dream: Successes and Failures of Post-war Immigration. London: Atlantic Books.

Harriss, Katherine and Alison Shaw. (2008). Kinship obligations, gender and the life course: Re-writing migration from Pakistan to Britain. In Virinder S. Kalra (ed.) Pakistani Diasporas: Culture, Conflict, and Change. Oxford: Oxford University Press. 19-42.

Kalman, Judith. (2005). Discovering Literacy: Access Routes to Written Culture for a Group of Women in Mexico. Hamburg: UNESCO Institute for Education. 
Krzyżanowski, Michal. (2008). Analysing focus group discussions. In Ruth Wodak and Michal Krzyżanowski (eds) Qualitative Discourse Analysis in the Socials Sciences Basingstoke: Palgrave Macmillan. 162-181.

Krzyżanowski, Michal and Ruth Wodak. (2011). Political strategies and language policies: The 'rise and fall' of the EU Lisbon Strategy and its implications for the Union's multilingualism policy. Language Policy 10(2), 155-136

Levitt, P. (2016) Social Remittances: How migrating people drive migrating culture. In Triandafyllidou, A. (Ed), Routledge Handbook of Immigration and Refugee Studies. (pp. 223228). Oxon: Routledge.

Lothers, M. and Lothers, L. (2007). Pahari/Potwari Survey report. FLA Language and culture series, No. 2 Rawalpindi, Pakistan: Frontier Language Institute.

Makoni, S. and Mashri, P. (2007). Critical historiography: Does language planning in Africa need a construct of language as part of its theoretical apparatus? In S. Makoni \& A. Pennycook (Eds), Disinventing and reconstituting languages (pp. 62-89). Clevedon: Multilingual Matters.

Maybin, J. (2000). The new literacy studies: Context, intertextuality and discourse. In D. Barton, M. Hamilton, \& R. Ivanič (Eds), Situated literacies: Reading and writing in context (pp. 197-209). London: Routledge.

Reisigl, Martin and Ruth Wodak. (2009) The discourse-historical approach (DHA). In Ruth Wodak and Michael Meyer (eds), Methods of Critical Discourse Analysis (2 $2^{\text {nd }}$ ed.) (pp. 87-122). London: Sage.

Street, Brian. (1984). Literacy in theory and practice. Cambridge: Cambridge University Press. 
Tusting, K. (2000). The new literacy studies and time: An exploration. In D. Barton, M Hamilton, \& R. Ivanič (Eds.) Situated Literacies: Reading and Writing in Context (pp. 35-53). London: Routledge.

UNICEF. (2013). "Global Initiative on Out-of-School Children.” New York: UNICEF.

van Dijk, Teun A. (1984). Prejudice in Discourse. Amsterdam: Benjamins

Wodak, Ruth. 2008. Introduction: Discourse studies - important concepts and terms. In Ruth Wodak and Michal Krzyżanowski (eds), Qualitative discourse analysis in the social sciences. Basingstoke: Plagrave Macmillan. 1-29.

Wodak, Ruth. 2011. 'Us' and 'them': inclusion and exclusion - discrimination via discourse. In Gerard Delanty, Ruth Wodak and Paul Jones (eds), Identity, Belonging and Migration. Liverpool: University of Liverpool Press. 54-77

Wodak, Ruth., and Salomi Boukala. 2015. (Supra)national identity and language: rethinking national and European migration policies and the linguistic integration of migrants. Annual Review of Applied Linguistics, 35, 253-273. 